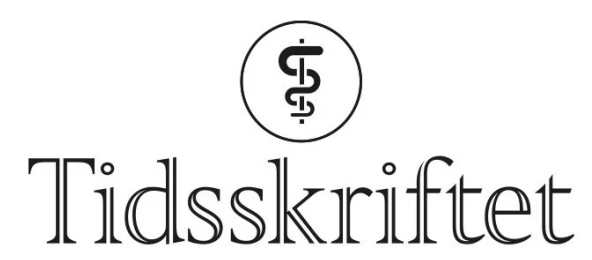

DEN NORSKE LEGEFORENING

\title{
Transkranial ultralydovervåking ved hjerneslag
}

KRONIKK

\section{LARS THOMASSEN}

lathom2@online.no

Lars Thomassen er spesialist i nevrologi, professor emeritus ved Universitetet i Bergen, tidligere overlege ved Nevrologisk avdeling og nå forsker ved Nevroklinikken, Haukeland universitetssjukehus.

Forfatteren har fylt ut ICMJE-skjemaet og oppgir ingen interessekonflikter.

\section{ANNETTE FROMM}

Annette Fromm er ph.d. (ultralyddiagnostikk), europeisk M.Sc. (stroke medicine), spesialist i nevrologi og overlege ved Nevrologisk avdeling, Haukeland universitetssjukehus.

Forfatteren har fylt ut ICMJE-skjemaet og oppgir ingen interessekonflikter.

\section{SANDER AARLI}

Sander Aarli er ph.d.-kandidat ved Universitetet i Bergen og arbeider med ultralydovervåking ved Nevrologisk avdeling, Haukeland universitetssjukehus.

Forfatteren har fylt ut ICMJE-skjemaet og oppgir ingen interessekonflikter.

\section{NICOLA LOGALLO}

Nicola Logallo er ph.d.(transkranial ultralyddiagnostikk), europeisk M.Sc. (stroke medicine), spesialist i nevrologi og overlege ved Nevrokirurgisk overvåkingsavdeling, Haukeland universitetssjukehus.

Forfatteren har fylt ut ICMJE-skjemaet og oppgir ingen interessekonflikter.

Ved akutt hjerneslag er hjernens blodsirkulasjon ustabil og hjernen i krise. Skal vi være fornøyd med et røntgenologisk øyeblikksbilde ved innleggelsen, eller trenger vi også en overvåking av hjernens blodsirkulasjon over tid? 


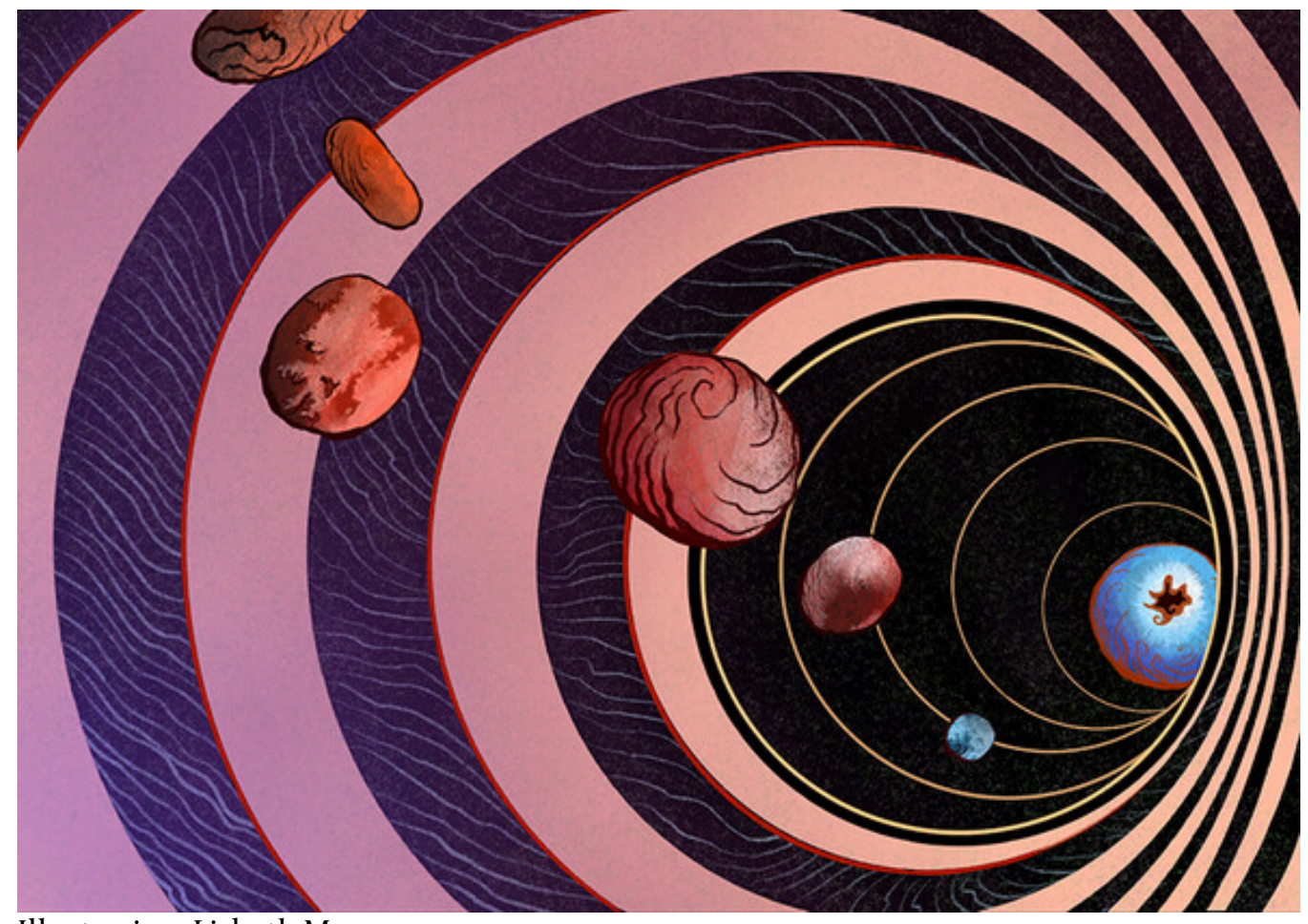

Illustrasjon: Lisbeth Moen

Når pasienter med symptomer på akutt hjerneinfarkt eller hjerneblødning ankommer sykehuset, foretas umiddelbart radiologisk bildediagnostikk med CT eller MR for å sikre riktig akuttbehandling. Når pasienten deretter kommer til slagovervåkingen, har man rikelig informasjon om blodårene, blodgjennomstrømningen i hjernen og hjernevevet. Slagovervåkingen er imidlertid tradisjonelt begrenset til overvåking av støttefunksjoner som hjertefunksjon, blodtrykk, oksygenmetning, temperatur, blodsukker og væskebalanse, mens cerebral sirkulasjon ikke overvåkes systematisk. Som grunnlag for videre behandling har man derved en patofysiologisk status presens fra akuttmottak, men lite eller ingen informasjon om den vaskulære utviklingen de neste kritiske timene.

\section{Transkranial ultralyd}

Transkranial ultralyd er en ikke-invasiv metode for overvåking av cerebral sirkulasjon ved sykesengen (1-3). Repeterte dupleksundersøkelser eller kontinuerlig dopplermonitorering gir mulighet for patofysiologisk forløpskontroll, som praktisk sett ikke kan gjennomføres med CT eller MR. Ultralydundersøkelsene kan tilpasses pasientens sykdom og sykdommens alvorlighetsgrad.

Kartleggingen starter med transkranial dupleksunders $ø$ kelse, som viser fargekodet blodstrøm i arteriene samtidig med en dopplerkurve som viser strømningshastigheter og hemodynamikk. Denne undersøkelsen gjentas ved behov. Kontinuerlig transkranial dopplermonitorering med bilateralt eller unilateralt fikserte ultralydprober (hodebånd) gir en kontinuerlig dopplerkurve som gjenspeiler hemodynamiske endringer, som for eksempel under rekanalisering eller reokklusjon (4,.5).

\section{Hjerneinfarkt}

Intravenøs trombolytisk behandling ved arterielle okklusjoner gir en høy grad av rekanalisering, hemodynamisk normalisering og klinisk bedring. Tilstanden er imidlertid ustabil, og rundt $10 \%$ av pasientene får tidlig klinisk forverring. Hemodynamiske faktorer spiller her en nøkkelrolle, men årsaken er i de fleste tilfellene uavklart (ㅁ). Rundt $30 \%$ av pasientene med påvist tidlig rekanalisering kan oppleve en reokklusjon med hemodynamisk krise og klinisk forverring $(7, \underline{8})$. Med dopplermonitorering kan man følge 
graden av rekanalisering og eventuell reokklusjon i sanntid over flere timer. Selv om godkjente retningslinjer anfører at platehemmere er kontraindisert de første 24 timene etter trombolyse, kan dopplerfunn styrke indikasjonen for tidlig antitrombotisk behandling. Kasuistiske meddelelser indikerer at også gjentatt intravenøs trombolytisk behandling kan være trygt ved klinisk forverring de første timene etter første dose (9).

Intraarteriell trombektomi gir som regel god rekanalisering, men ikke alltid adekvat vevsperfusjon (no reflow phenomenon). Rekanalisering er heller ikke alltid uproblematisk og kan resultere i et cerebralt hyperperfusjonssyndrom med blødningskomplikasjoner, hjerneødem, infarktvekst og klinisk forverring. Kliniske symptomer er ofte forsinket og uklare ved et hjerneinfarkt. Tidlig hemodynamisk informasjon de første timene er derfor vesentlig (므). Dopplermonitorering kan demonstrere slike hemodynamiske endringer og bidra til rasjonell behandling.

En precerebral okklusjon gir fokalt redusert blodstrøm, men graden av perfusjonssvikt og faren for cerebral iskemi avhenger av kollateralsirkulasjonen. Transkranial dopplerundersøkelse kan vise om Willis' pulsårering er funksjonelt intakt, som sentrale kollateraler, og om det er en perfusjonsforskyvning (flow diversion) til leptomeningeale perifere kollateraler (11). Graden av kollateralsirkulasjon er av betydning for intensiteten av blodtrykksbehandlingen.

\section{«Ultralyd kan benyttes ved sykesengen under pågående generell overvåking, kan brukes hyppig og er ikke til belastning for pasientene»}

Ved precerebrale okklusjoner og redusert cerebral perfusjon kan graden av restkapasitet for vasodilatasjon (autoregulering) være avgjørende. Dopplerhastighetsmåling i proksimale arteriesegment under dilatasjon av perifere arteriesegment ved hjelp av intravenøs acetazolamidinjeksjon (Diamox-test) gir svar på graden av tapt dilatasjonsevne (vasoreaktivitet) (12). Ved opphevet vasoreaktivitet er cerebral perfusjon passivt avhengig av systemblodtrykket, og blodtrykket må da ikke senkes.

Akutt hjerneinfarkt skyldes som oftest tromboembolisme, men utgangspunktet for embolusen er ukjent. Dopplermonitorering er den eneste metoden som kan registrere sirkulerende mikroemboluser in vivo (13). Pågående embolisering er hyppigst umiddelbart etter hjerneinfarktet, og undersøkelsen bør derfor utføres tidligst mulig $(\underline{14}, 15)$. Bilaterale emboluser indikerer en kardial eller systemisk kilde, unilaterale emboluser indikerer at kilden er en carotisstenose. Påvisning av mikroemboluser har dermed betydning både for valg av antitrombotisk behandling og for behandlingsintensiteten.

\section{Hjerneblødning}

Ved hjerneblødning fører initialt økende hematomvolum til økende hjerneskade. Det er svært godt samsvar mellom transkranial dupleksunders $ø$ kelse av blødningsvolum og CTundersøkelser, og gjentatte dupleksundersøkelser gir tilfredsstillende informasjon om tidlig hematomvekst og midtlinjeforskyvning (16,17.). Informasjonen har prognostisk betydning og kan gi grunnlag for fors $ø \mathrm{k}$ med hemostatisk behandling eller intensivert blodtrykksbehandling.

Vasospasme og påfølgende iskemisk hjerneskade ses sjelden ved primær hjerneblødning, men ofte når det i tillegg foreligger intraventrikulært blod $(\underline{18}, 19)$.). Ventriklene kommuniserer med subaraknoidalrommet, og det kan utvikle seg en svært ustabil tilstand, som ved primær subaraknoidalblødning. Nevrokirurgisk overvåking omfatter her repeterte ultralydundersøkelser for å fange opp tegn til økende vasospasme og behandling 


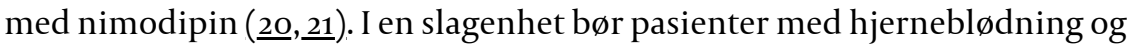

intraventrikulært blod tilbys tilsvarende ultralydovervåking for å unngå en mulig iskemisk tilleggsskade i hjernen.

\section{Overvåk hjernen med ultralyd}

Akutt nevrovaskulær sykdom kan være livstruende, og umiddelbar intensiv overvåking og behandling er nødvendig. Lettere tilfeller er ikke nødvendigvis livstruende, men cerebral sirkulasjon er alltid ustabil og hjernens funksjon er alltid truet. I det tidlige forløpet ville gjentatte radiologiske undersøkelser være ønskelig. CT har imidlertid begrensninger på grunn av stråle- og kontrastmiddelbelastning, MR er vanligvis ikke raskt tilgjengelig og både CT og MR krever forflytning av pasientene. Radiologiske metoder er derfor ikke egnet til overvåking. Ultralyd kan til sammenlikning benyttes ved sykesengen under pågående generell overvåking, kan brukes hyppig og er ikke til belastning for pasientene.

I en akutt situasjon med raske patofysiologiske endringer kan imidlertid transkranial ultralyddiagnostikk være vanskelig. Diagnostikken forutsetter korrekte målemetoder og gode kunnskaper i nevrovaskulær anatomi og fysiologi. Endeproduktet er en spektral pulskurve og fysiologiske strømningsvariabler som må tolkes. Dette er nok noe av grunnen til at relativt få klinikere virkelig behersker metoden og at mange fortsatt er skeptiske til

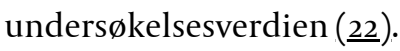

Klinisk nevrosonologi er kritisert for å være svært operatøravhengig. Kritikken understreker behovet for systematisk utdanning inkorporert i daglig klinisk praksis og $\mathrm{i}$ teoretisk videreutdanning $(\underline{2} 3,24)$. Ultralydresultatene gir rom for tolkning, men sammen med informasjon fra initial CT/MR og patofysiologisk forståelse av kompleksiteten i vaskulær nevrologi, understøtter resultatene terapeutiske avgjørelser og prognostiske vurderinger. I erfarne hender gir metodene praktisk nyttig informasjon om og for pasienten over tid.

Klinisk nevrosonologi og transkranial ultralydovervåking er etter vår erfaring fra Norsk hjerneslagforening dårlig utviklet i Norge. Det er på tide å oppgradere norske slagenheter til å ta et større ansvar for hjerneslagets første kritiske timer.

\section{LITTERATUR}

1. Naqvi J, Yap KH, Ahmad G et al. Transcranial Doppler ultrasound: a review of the physical principles and major applications in critical care. Int J Vasc Med 2013; 2013: 629378. [PubMed][CrossRef]

2. Montrief T, Alerhand S, Jewell C et al. Incorporation of Transcranial Doppler into the ED for the neurocritical care patient. Am J Emerg Med 2019; 37: 1144-52. [PubMed][CrossRef]

3. Bonow RH, Young CC, Bass DI et al. Transcranial Doppler ultrasonography in neurological surgery and neurocritical care. Neurosurg Focus 2019; 47: E2. [PubMed][CrossRef]

4. Thomassen L, Waje-Andreassen U, Naess $\mathrm{H}$ et al. Doppler ultrasound and clinical findings in patients with acute ischemic stroke treated with intravenous thrombolysis. Eur J Neurol 2005; 12: 4625. [PubMed][CrossRef]

5. Molina CA. Monitoring and imaging the clot during systemic thrombolysis in stroke patients. Expert Rev Cardiovasc Ther 2007; 5: 91-8. [PubMed][CrossRef]

6. Tisserand M, Seners P, Turc G et al. Mechanisms of unexplained neurological deterioration after intravenous thrombolysis. Stroke 2014; 45:3527-34. [PubMed][CrossRef]

7. Alexandrov AV, Grotta JC. Arterial reocclusion in stroke patients treated with intravenous tissue plasminogen activator. Neurology 2002; 59: 862-7. [PubMed][CrossRef]

8. Baizabal-Carvallo JF, Alonso-Juarez M, Samson Y. Clinical deterioration following middle cerebral artery hemodynamic changes after intravenous thrombolysis for acute ischemic stroke. J Stroke Cerebrovasc Dis 2014; 23: 254-8. [PubMed][CrossRef]

9. Cappellari M, Tomelleri G, Carletti M et al. Intravenous thrombolysis on early recurrent cardioembolic stroke: 'Dr Jekyll' or 'Mr Hyde'? Blood Coagul Fibrinolysis 2012; 23: 78-81. [PubMed] 
10. Lin YH, Liu HM. Update on cerebral hyperperfusion syndrome. J Neurointerv Surg 2020; 12: 788-93. [PubMed][CrossRef]

11. Saqqur M, Khan K, Derksen C et al. Transcranial doppler and transcranial color duplex in defining collateral cerebral blood flow. J Neuroimaging 2018; 28: 455-76. [PubMed][CrossRef]

12. Müller M, Voges M, Piepgras U et al. Assessment of cerebral vasomotor reactivity by transcranial Doppler ultrasound and breath-holding. A comparison with acetazolamide as vasodilatory stimulus. Stroke 1995; 26: 96-100. [PubMed][CrossRef]

13. Bazan R, Luvizutto GJ, Braga GP et al. Relationship of spontaneous microembolic signals to risk stratification, recurrence, severity, and mortality of ischemic stroke: a prospective study. Ultrasound J 2020; 12: 6. [PubMed][CrossRef]

14. Best LMJ, Webb AC, Gurusamy KS et al. Transcranial doppler ultrasound detection of microemboli as a predictor of cerebral events in patients with symptomatic and asymptomatic carotid disease: A systematic review and meta-analysis. Eur J Vasc Endovasc Surg 2016; 52: 565-80. [PubMed][CrossRef]

15. Kargiotis O, Psychogios K, Safouris A et al. The role of transcranial doppler monitoring in patients with multi-territory acute embolic strokes: A review. J Neuroimaging 2019; 29:309-22. [PubMed] [CrossRef]

16. Pérez ES, Delgado-Mederos R, Rubiera M et al. Transcranial duplex sonography for monitoring hyperacute intracerebral hemorrhage. Stroke 2009; 40: 987-90. [PubMed][CrossRef]

17. Camps-Renom P, Méndez J, Granell E et al. Transcranial duplex sonography predicts outcome following an intracerebral hemorrhage. AJNR Am J Neuroradiol 2017; 38: 1543-9. [PubMed][CrossRef]

18. Khatri IA, Verma N, Alkawi A et al. Cerebral vasospasm in intracerebral hemorrhage-case report. J Vasc Interv Neurol 2009; 2:139-41. [PubMed]

19. Regula JU, Schill J, Ringleb PA et al. Cerebral vasospasm and delayed cerebral ischemia in intraventricular hemorrhage. Neurocrit Care 2014; 20: 460-5. [PubMed][CrossRef]

20. Kumar G, Shahripour RB, Harrigan MR. Vasospasm on transcranial Doppler is predictive of delayed cerebral ischemia in aneurysmal subarachnoid hemorrhage: a systematic review and metaanalysis. J Neurosurg 2016; 124: 1257-64. [PubMed][CrossRef]

21. Samagh N, Bhagat $H$, Jangra K. Monitoring cerebral vasospasm: How much can we rely on transcranial Doppler. J Anaesthesiol Clin Pharmacol 2019;35:12-8. [PubMed]

22. Alexandrov AV, Sloan MA, Tegeler CH et al. Practice standards for transcranial Doppler (TCD) ultrasound. Part II. Clinical indications and expected outcomes. J Neuroimaging 2012; 22: 215-24. [PubMed][CrossRef]

23. Nedelmann M, Stolz E, Gerriets T et al. Consensus recommendations for transcranial color-coded duplex sonography for the assessment of intracranial arteries in clinical trials on acute stroke. Stroke 2009; 40:3238-44. [PubMed][CrossRef]

24. Robba C, Poole D, Citerio G et al. Brain ultrasonography consensus on skill recommendations and competence levels within the critical care setting. Neurocrit Care 2020;32: 502-11. [PubMed] [CrossRef]

Publisert: 10. august 2021. Tidsskr Nor Legeforen. DOI: 10.4045/tidsskr.21.018o

Mottatt 3.3.2021, første revisjon innsendt 18.3.2021, godkjent 7.4.2021.

(C) Tidsskrift for Den norske legeforening 2023. Lastet ned fra tidsskriftet.no 26. april 2023. 